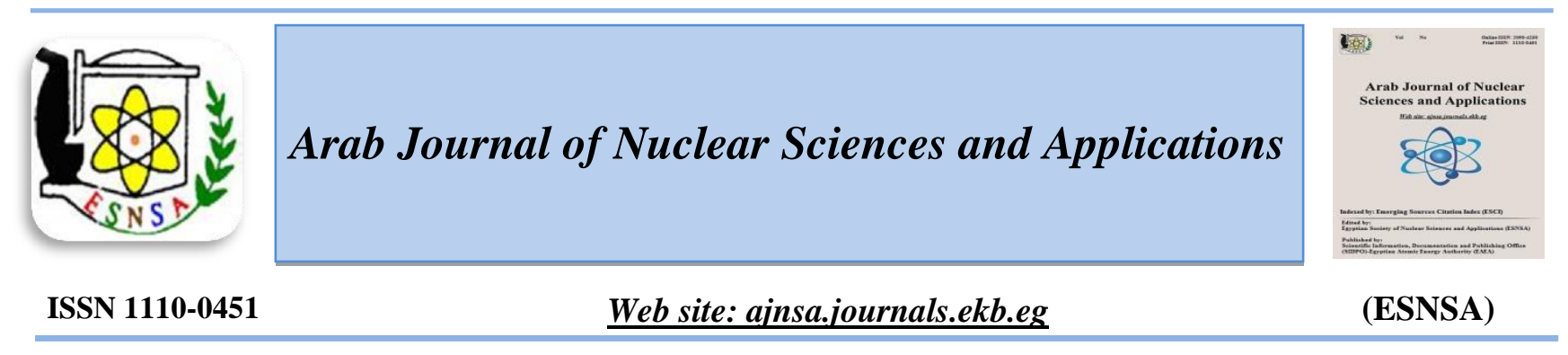

\title{
An Assessment of Impact Toughness of the Pressure Vessel Steel A533-B and its 308 Austenitic Stainless Steel Weld Metal
}

\author{
${ }^{(1)}$ Omyma H. Ibrahim, and ${ }^{(2)}$ Ibrahim S. Ibrahim \\ ${ }^{(1)}$ Metallurgy Department, Nuclear Research Center, Atomic Energy Authority, Egypt \\ ${ }^{(2)}$ Egyptian Nuclear and Radiological Regulatory Authority, Egypt
}

The steel A533-B is a low alloy steel used as a structural material for the construction of light water nuclear reactor pressure vessels. It is normally cladded with the $\mathbf{3 0 8}$ austenitic stainless steel weld metal overlay for protection against extension of surface flaws generating during operation. In this investigation, the impact toughness of the A533-B steel and its 308 weld metal were evaluated. The microstructure of the A533-B steel consisted of bainitic structure while that of the 308 weld metal comprised austenite with ferrite phase of about $5 \%$. The impact toughness was assessed using an instrumented impact testing machine at temperatures between -196 and $300^{\circ} \mathrm{C}$. The determined impact toughness parameters involved the total impact fracture energy, the energy expended in the fracture crack initiation and crack propagation, the ductile to brittle transition temperature as well as the dynamic yield strength. The A533-B steel exhibited distinct ductile to brittle transition behavior with superior resistance to ductile fracture at high test temperatures. In contrast, the 308 weld metal did not display such transition. However, it showed low energy ductile fracture performance with evident resistance to brittle fracture even at low test temperatures. The findings were substantiated with the load-time traces derived from the instrumented impact tests as well as the fracture surface morphology. The results were discussed in relation to the difference in microstructure and flow properties of the examined steels.

\section{Introduction}

Keywords: A533-B steel, 308 weld metal, impact toughness

Nuclear power stations use steel pressure vessels to house the core of the reactor. Accordingly, the safe operation of the nuclear reactor depends on the integrity of the pressure vessel. This property depends on the ability of the steel to maintain adequate amount of toughness in order to resist brittle fracture which is considerably enhanced by neutron irradiation [1].

In order to minimize the risk of brittle fracture, the inner surface of the nuclear reactor pressure vessel is normally cladded with austenitic stainless steel weld metal overlay. Furthermore, this tough overlay cladding on the interior of a reactor pressure vessel could mitigate damage that might arise during certain overcooling transients e.g. PTS (pressurized thermal shock). PTS is considered one of the most severe events that may affect the structural integrity of the pressure vessel and could lead to the failure of the reactor. The potential benefit of the weld overlay cladding is that it could keep developed surface cracks from growing. This may take place either by impeding the initiation of the cracks or by arresting propagating cracks [2]. The weld overlay cladding has a duplex phase structure, comprising a discontinuous net-like structure of delta-ferrite phase in an austenitic matrix. The major role of delta-ferrite in austenitic stainless steel weld is to avoid hot cracking or solidification cracking. ASME Boiler and Pressure vessel code calls for minimum of $5 \%$ delta-ferrite in austenitic steel welds to avoid hot cracking. If

Corresponding author: omymaibrahim95@gmail.com

DOI: $10.21608 / a j n s a .2019 .6220 .1136$

(C) Scientific Information, Documentation and Publishing Office (SIDPO)-EAEA 
the delta-ferrite content is increased, the tendency of embrittlement of the weld increases, which means low toughness values of the weld [3].

The phenomenon of hot cracking or solidification cracking is of concern in austenitic stainless steel welds. Solidification cracking results from the segregation of a low melting point liquid along the grain boundaries during last stage of solidification. If sufficient stresses are generated before the final solidification, the boundaries may separate to form cracks. The presence of retained ferrite in the austenitic stainless steel weld effectively prevents hot cracking. This is because the higher solubility of impurities in ferrite than in austenite results in less segregation of low melting impurities which would help in preventing hot cracking. In addition, delta-ferrite has a lower thermal coefficient of expansion, which helps in the reduction of thermal stresses [4].

Impact toughness of steels is primarily dependent on its microstructure which is determined by the chemical composition and heat treatment. Microstructural parameters of steels incorporate dislocation density, grain size as well as volume fraction, shape, and size of second phase particles (carbides, inclusions). These constituents govern the level of toughness by determining the propensity for cleavage and/or ductile fracture processes.

The present investigation determines the impact toughness of the conventional ferritic pressure vessel steel; A533-B and its relevant 308 austenitic stainless steel weld metal. The relation between the impact toughness with the microstructure and flow properties of the studied materials was interpreted using the results of the instrumented impact tests and fracture surface morphology.

\section{Experimental}

The materials used in this investigation included A533-B pressure vessel steel plate of $10 \mathrm{~mm}$ thickness and 308 stainless steel weld metal as rutile coated shielded arc electrode of $3 \mathrm{~mm}$ diameter for the weld deposit. A 308 weldment was made by shielded metal arc welding (SMAW) using V-groove joint between the two plates of the A533-B steel.

Table (1): Chemical composition of investigated materials, wt $\%$

Standard Charpy V-notch specimens were impact tested using an instrumented impact machine (AMSLER-RKP 300) with a total energy of 300 Joule and a hammer velocity of $5.2 \mathrm{~m} / \mathrm{s}$. Tests were conducted in a temperature range between 196 and $300^{\circ} \mathrm{C}$ to generate full transition curves. The produced load-time traces were utilized to obtain dynamic fracture loads and crack initiation and propagation energies. Optical micrographs were obtained by etching polished specimens in a solution of $4 \%$ picric acid in methanol for the A533-B steel and aqua regia reagent for the 308 weld metal. Fracture surface was examined using a scanning electron microscope (SEM, Joel, JSM400).

\section{Results}

\section{Microstructure}

The microstructure of the investigated materials is shown in Fig. (1). The A533-B steel displayed bainite structure characterized by lath formation arranged in packets subdividing prior austenite grains, Fig.1a. The 308 weld metal microstructure involved skeletal network of vermicular ferrite of about $5 \%$ enveloped by austenitic matrix, Fig.(1b). The difference in the microstructure between the two steels can be correlated with the difference in the chemical composition and applied heat treatment. The low alloy A533-B steel was subjected to an austenitizing, water quenching and tempering heat treatment processes, while the 308 weld metal experienced weld-melt solidification and subsequent cooling of the weld metal to room temperature.

Table (1): Chemical composition of investigated materials, wt $\%$

\begin{tabular}{|c|c|c|c|c|c|c|c|c|c|c|}
\hline Material & $\mathrm{C}$ & $\mathrm{Si}$ & $\mathrm{Mn}$ & $\mathrm{Mo}$ & $\mathrm{Ni}$ & $\mathrm{Cr}$ & $\mathbf{P}$ & $\mathrm{S}$ & $\mathrm{Cu}$ & $\mathrm{Fe}$ \\
\hline A533-B & $\mathbf{0 . 2 5}$ & $\mathbf{0 . 2 5}$ & $\mathbf{1 . 3 3}$ & $\mathbf{0 . 5 1}$ & $\mathbf{0 . 6 5}$ & $\mathbf{0 . 1 5}$ & $\mathbf{0 . 0 1 1}$ & $\mathbf{0 . 0 1}$ & $\mathbf{0 . 2 8}$ & bal \\
\hline 308 WM & $\mathbf{0 . 0 5}$ & $\mathbf{0 . 9 0}$ & $\mathbf{1 . 9 2}$ & $\mathbf{0 . 3 0}$ & $\mathbf{9 . 5 0}$ & $\mathbf{1 9 . 9 0}$ & $\mathbf{0 . 0 2 5}$ & $\mathbf{0 . 0 6}$ & - & bal \\
\hline
\end{tabular}



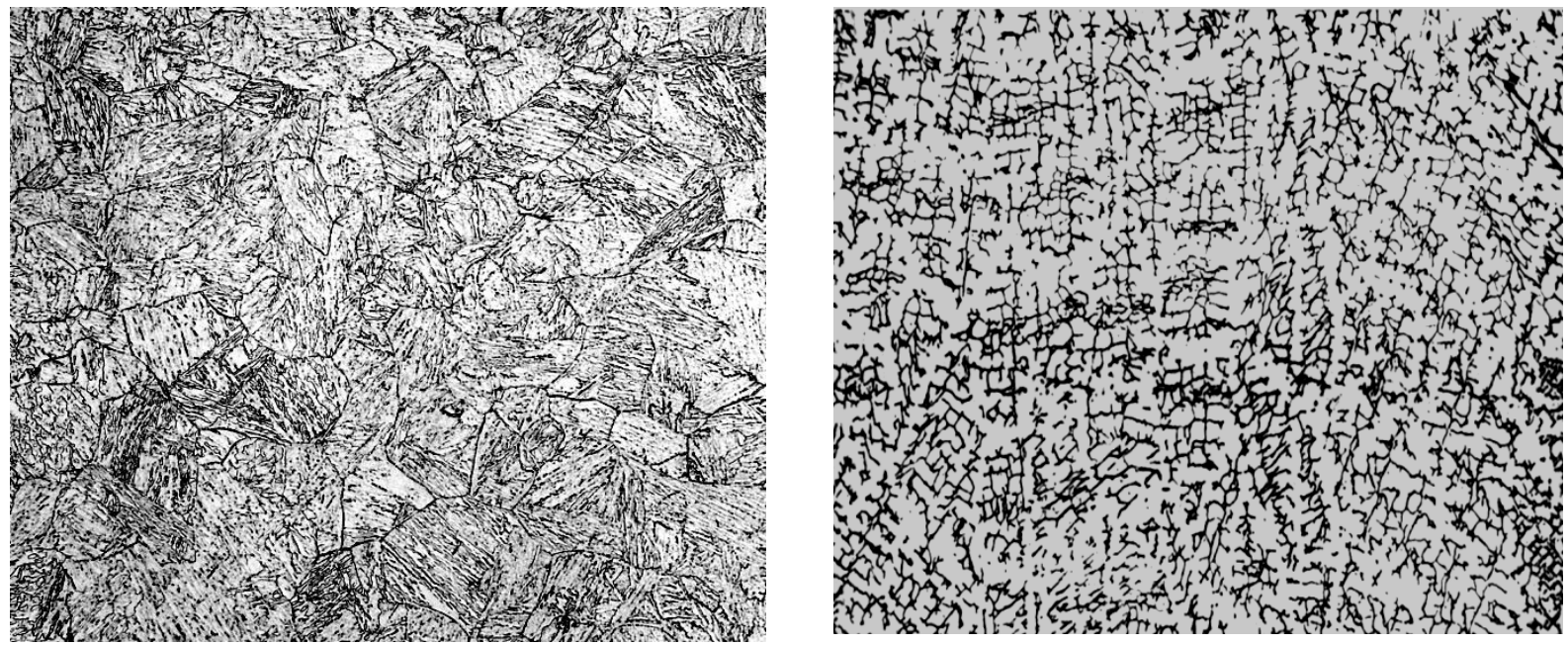

Fig. (1): Optical micrograph showing microstructure of the tested materials,

(a) A533-B steel, X200

\section{Impact toughness results}

The impact test results for both materials are shown in Figs. (2-4). Figure (2) presents the variation of the total impact fracture energy with the test temperature. As can be seen, the A533-B steel displays a typical ductile-to-brittle transition behavior characteristic of ferritic steels. However, the 308 weld metal did not experience such transition behavior, but showed only a gradual decrease in the impact fracture energy. The upper shelf energy (USE) and the ductile to brittle transition temperature (DBTT), as evaluated at the intersection point of half the value of upper shelf energy with the transition curve, were determined. The A533-B low alloy steel had a much higher USE than that of the 308 weld metal (135 vs. 70J), Table (2). The DBTT of the A533-B low alloy steel had a value of $25^{\circ} \mathrm{C}$. No DBTT value could be determined for the 308 weld metal since it did not experience ductile to brittle fracture transition. The results deduced from Fig. (2), indicates that the A533-B low alloy steel has superior resistance to ductile fracture at high test temperatures and that the 308 weld metal acquires much more resistance to brittle fracture at low test temperatures.

Figure (3) shows typical load-time traces derived from the instrumented impact tests for both materials at $150{ }^{\circ} \mathrm{C}$ (upper shelf energy region). Both steels demonstrated fully ductile manner of fracture. In Figure (3), the $\mathrm{P}_{\mathrm{m}}$ and $\mathrm{P}_{\mathrm{y}}$ denote (b) 308 Weld metal, X200

dynamic maximum and yield loads, respectively. The area under the curve up to the point of $\mathrm{P}_{\mathrm{m}}$ represents the fracture initiation energy $E_{i}$, while the remaining area represents the fracture propagation energy $\mathrm{E}_{\mathrm{p}}$. Analysis of the load-time trace for A533-B low alloy steel Fig. (3a) shows that the ductile fracture initiation energy, $\mathrm{E}_{\mathrm{i}}$, was $30 \%$ of that of the total energy (45 vs. $135 \mathrm{~J}$ ), while that of the ductile fracture propagation energy was $70 \%$ of the total energy (90 vs. $135 \mathrm{~J})$, Table (2). The corresponding values for the 308 weld metal were ( 28 vs. $70 \mathrm{~J})$, i.e., $40 \%$ for the initiation energy $\left(\mathrm{E}_{\mathrm{i}}\right)$ and $(42$ vs. $70 \mathrm{~J})$, i. e., $60 \%$ for the propagation energy $\left(E_{p}\right)$, Fig. (3b). This means that, for the two steels, the ductile crack initiation process has consumed less energy than that of the ductile crack propagation process, i.e. most of the total fracture energy was expended in the crack propagation.

Inspection of the load-time traces at $-100{ }^{\circ} \mathrm{C}$ (lower shelf energy region), Fig. (4), shows complete brittle fracture feature for the A533-B steel with a total energy of $10 \mathrm{~J}$, Fig. (4 a). On the contrary, the 308 weld metal exhibits fully ductile fracture aspect with an entire energy of $30 \mathrm{~J}$, Fig. (4 b). This supports the result that the 308 weld metal attains a higher resistance against brittle fracture at low test temperatures than the A533-B steel. 


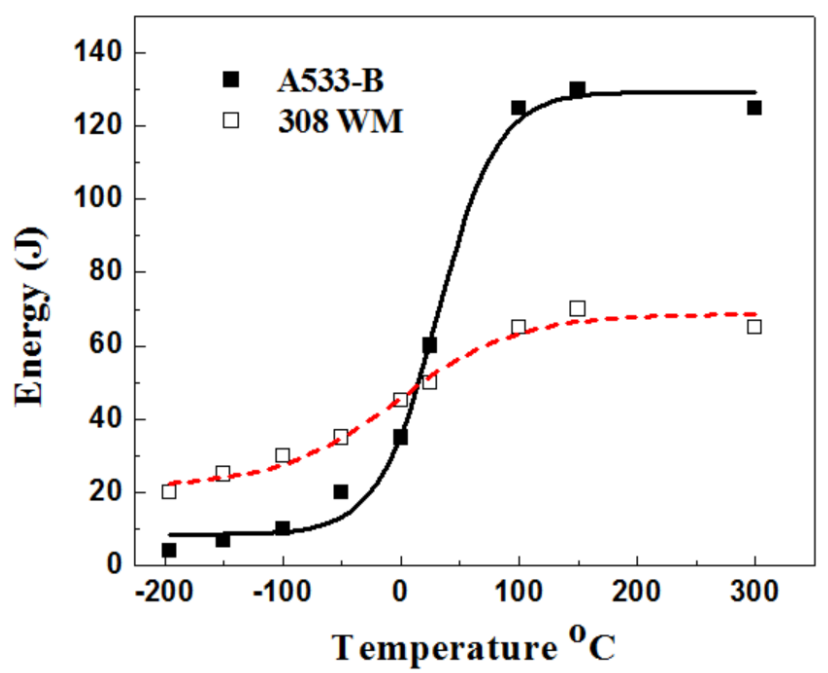

Fig. (2): Impact transition curves of investigated materials

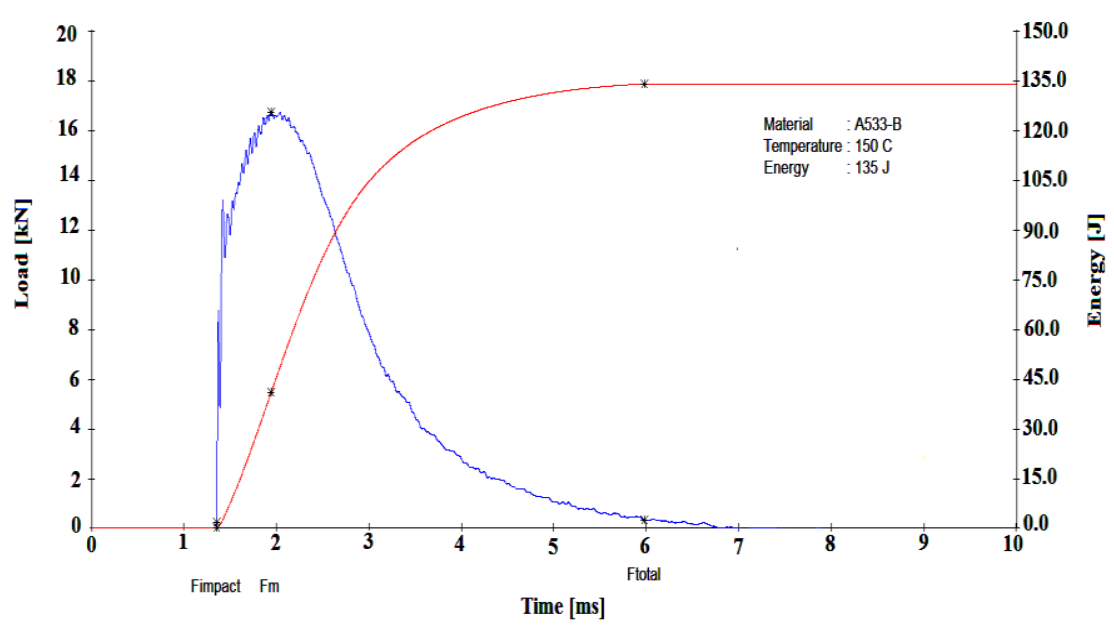

(a)

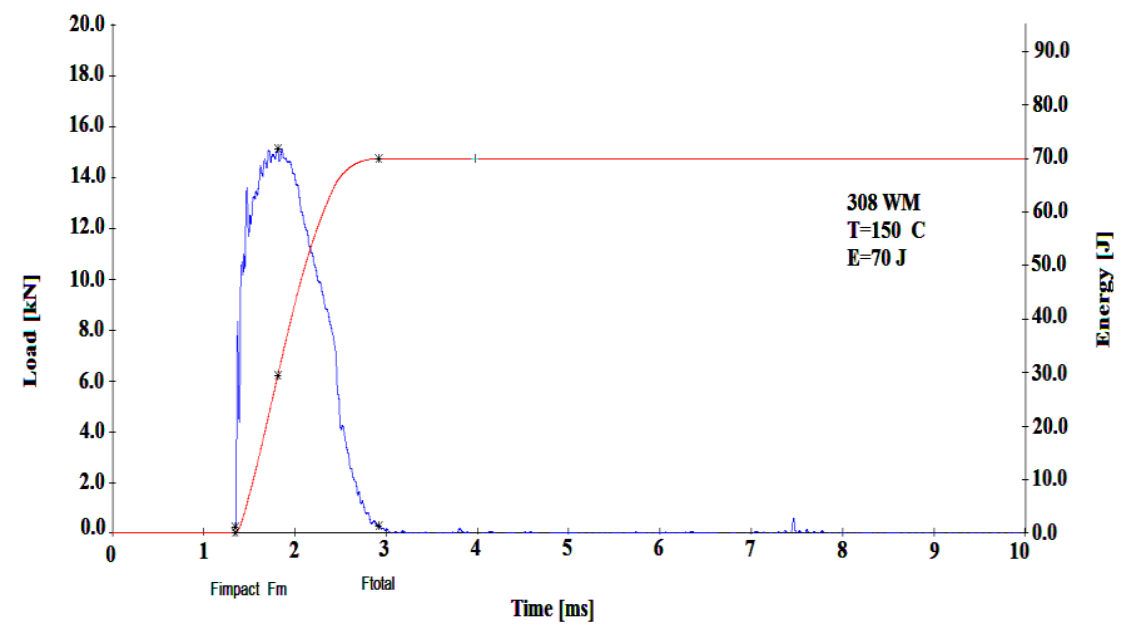

(b)

Fig. (3): Load-time traces at $150^{\circ} \mathrm{C}$ (a) A533-B (b) $308 \mathrm{WM}$ 


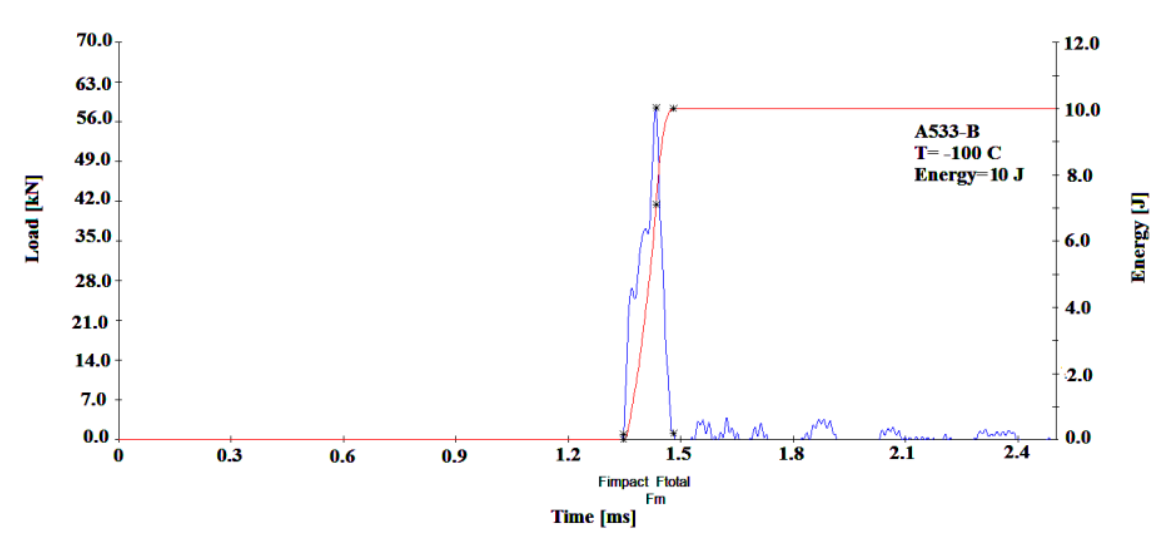

(a)

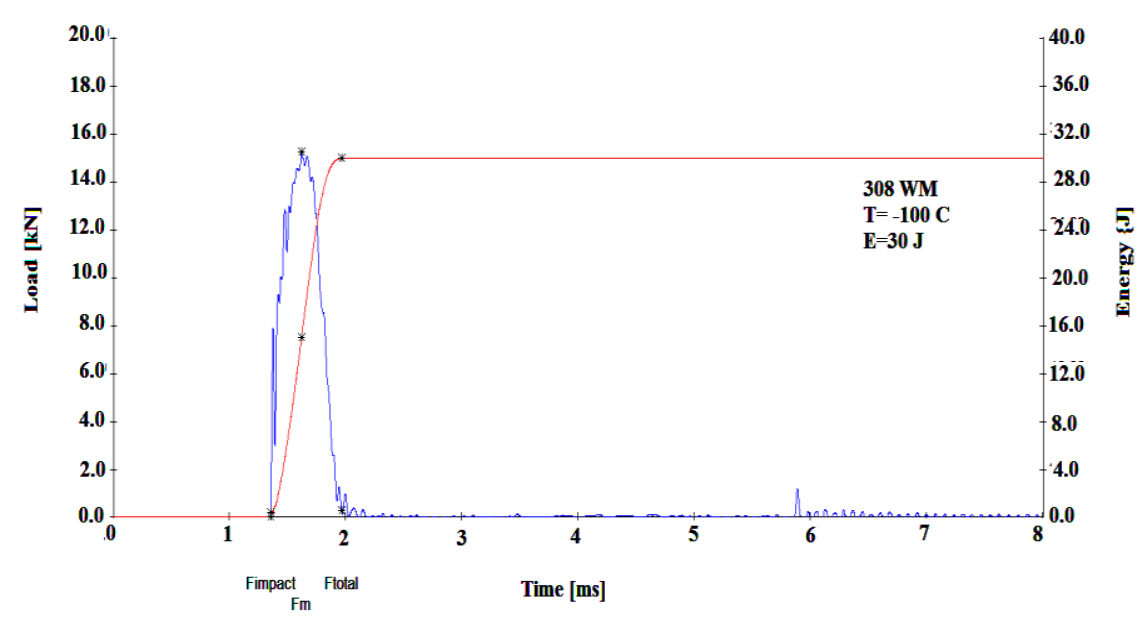

(b)

Fig. (4): Load-time traces at $-100{ }^{\circ} \mathrm{C}$ (a) A533-B, (b) $308 \mathrm{WM}$

Table (2): Impact test values of investigated steels at $150{ }^{\circ} \mathrm{C}$

\begin{tabular}{lccrccc}
\hline \multicolumn{1}{c}{ material } & TT(C) & USE(J) & Ei(J) & Ep (J) Ei/Et(\%) & E p p/Et(\%) \\
\hline A533-B steel & 25 & 135 & 45 & 90 & 30 & 70 \\
308 Weld metal & - & 70 & 28 & 42 & 40 & 60 \\
\hline
\end{tabular}

Load-time traces can provide additional information about the flow properties of the investigated materials. The dynamic strain capacity can be identified through computing the ratio $\mathrm{P}_{\mathrm{y}} / \mathrm{P}_{\mathrm{m}}$ Fig (3). This ratio was found to be 0.6 and 0.8 for the A533-B steel and the $308 \mathrm{WM}$, respectively at $150{ }^{\circ} \mathrm{C}$. This indicates higher strain capacity for the A533-B steel in the upper shelf (ductile fracture) range. At $100{ }^{\circ} \mathrm{C}$ the $\mathrm{P}_{\mathrm{y}} / \mathrm{P}_{\mathrm{m}}$ ratio was raised to 0.8 for the A533-B steel and dropped to 0.6 for the 308 WM. Furthermore, the amount of deflection $(\delta)$ produced during the impact test, which presents a further indicator for the amount of dynamic strain capacity, was estimated at 150 and $-100{ }^{\circ} \mathrm{C}$. At $150{ }^{\circ} \mathrm{C}, \delta$ values were 0.55 and $0.20 \mathrm{~mm}$ for the A533-B and the $308 \mathrm{WM}$, respectively. The corresponding $\delta$ values decreased at $-100{ }^{\circ} \mathrm{C}$ to 0.02 and $0.10 \mathrm{~mm}$, respectively

Another deformation property which warrants mentioning is the dynamic yield strength. The dynamic yield strength $\left(\sigma_{\mathrm{yd}}\right)$ of the A533-B and 308 weld metal was determined at 150 and $-100{ }^{\circ} \mathrm{C}$ 
test temperatures, using to the following formula [5]:

$$
\sigma_{y d}=\frac{P_{y} L}{C B(W-a)^{2}}
$$

$\mathrm{P}_{\mathrm{y}}$ is the dynamic yield load, $\mathrm{B}$ is the specimen width, $\mathrm{W}$ is the specimen depth, a is the notch depth, $\mathrm{L}$ is the bend span and $\mathrm{C}$ is the constraint factor $(\approx 1.25) . \sigma_{y d}$ was found to be 550 and $600 \mathrm{MPa}$ for the A533-B and $308 \mathrm{WM}$ at $150{ }^{\circ} \mathrm{C}$ test temperature, respectively. The corresponding values of $\sigma_{\mathrm{yd}}$ at $-100{ }^{\circ} \mathrm{C}$ test temperature equaled 750 and $650 \mathrm{MPa}$, respectively. These values indicate that reducing the test temperature from 150 to $-100{ }^{\circ} \mathrm{C}$ has led to increasing the dynamic yield strength of the A533-B much more than that of $308 \mathrm{WM}$.

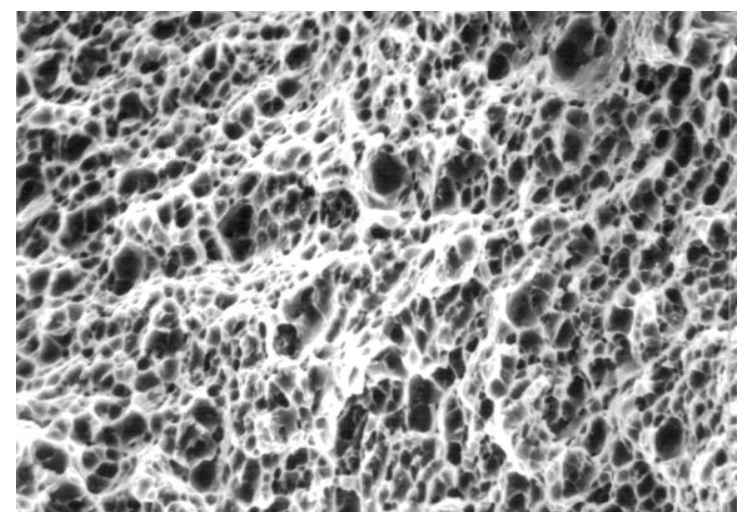

(a)A533-B

Fig. (5): SEM fractographs showing ductile fracture in specimens tested at $150{ }^{\circ} \mathrm{C}, \mathrm{X} 1000$

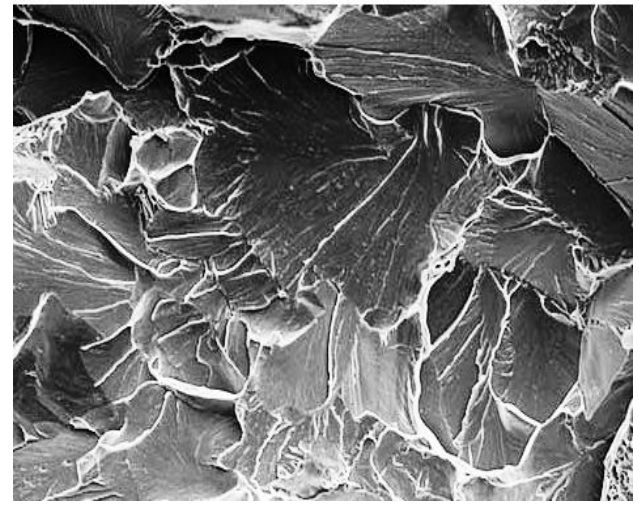

(a)A533-B Steel

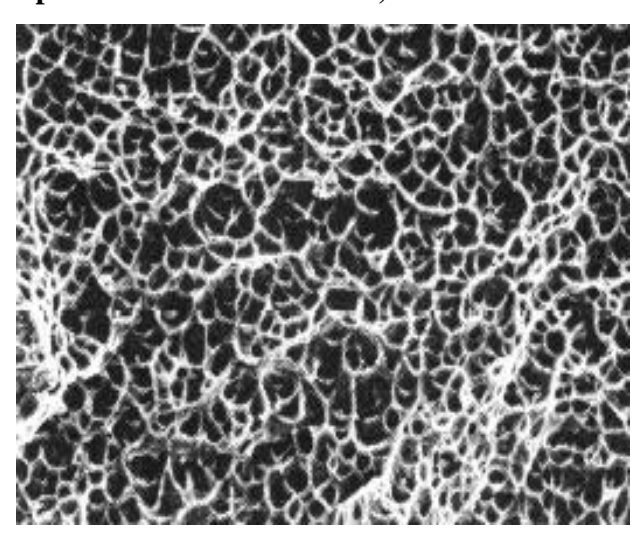

(b) $308 \mathrm{WM}$

\section{Fractography}

Figures 5 and 6 show scanning electron fragtographs of specimens tested at $150{ }^{\circ} \mathrm{C}$; upper shelf temperature range and at $-100{ }^{\circ} \mathrm{C}$; lower shelf temperature range. In Figures $(5 \mathrm{a}, \mathrm{b})$ the fracture surface reveals ductile mode of fracture characterized by microvoid coalescence. Both, fine dimples, in the case of A533-B steel Fig. (5a) and rather large dimples, in the case of 308 weld metal Fig. (5b), can be clearly observed. In Fig. (6 a), the fracture surface of A533-B steel displays cleavage mode of fracture characterized by facet-like arrangements with river patterns formed by cleavage lines and steps. Alternatively, fracture of the 308 weld metal Fig. (6b) proceeded by ductile pattern of fracture presenting finer dimpled appearance than that shown in Fig. (5b).

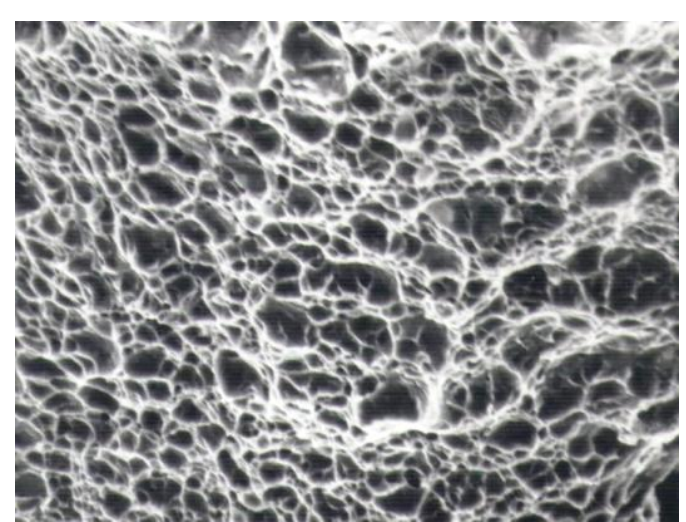

(b) $308 \mathrm{WM}$
Fig. (6): SEM fractographs showing brittle fracture (Fig. 6a) and ductile fracture (Fig. 6b) in specimens tested at $-100{ }^{\circ} \mathrm{C}$, X1000 


\section{Discussion}

The findings have shown that the low alloy A533-B steel with its bainitic microstructure demonstrated superior resistance to ductile fracture than the 308 weld metal at high test temperatures. Conversely, the 308 weld metal showed much higher fracture energy at low test temperatures. This variation in the fracture behavior of the two investigated steels can be related to the difference in their metallurgical parameters that include microstructural features and flow properties.

\section{Ductile fracture}

The higher upper shelf energy value of the low alloy A533-B steel as compared to that of the 308 weld metal (135 vs. $70 \mathrm{~J}$ ) indicates higher energy expenditure during ductile crack initiation and propagation processes. Table (2) showed that $E_{i}$ and $E_{p}$ of the A533-B steel exceed those of the 308 WM by 17 and $48 \mathrm{~J}$, respectively.

The micromechanism operating during ductile fracture involves crack initiation through nucleation of microvoids and then crack propagation by the growth and coalescence of these voids through plastic deformation of the surrounding matrix. In steels, the voids generally nucleate by decohesion of inclusions or fracture of second phase particles (carbides). Microvids first form around $\mathrm{MnS}$ inclusions through deboning of the steel-sulfide interface. After the growth stage, large voids link up (coalesce) to cause fracture with the help of the small voids that form around carbides [6].

As shown in Table (1), the carbon content of the A533-B steel is five times greater than that of the 308 weld metal $(0.25 \%$ vs. $0.05 \%)$. In contrast, the sulfur content of the 308 weld metal is six times greater than that of the A533-B steel (0.06\% vs. $0.01 \%$ ). This could result in higher carbide and lower inclusion density, respectively in the A533B steel than the 308 WM. Nevertheless, the alloy carbides formed during tempering of low alloy steels are of fine size and resistant to cracking than cementite carbides particles[6]. This could account for the relatively higher $\mathrm{E}_{\mathrm{i}}$ value of the A533-B steel than that of the $308 \mathrm{WM}$ (45 vs. 28J). In addition, the comparatively higher sulfur content of the 308 WM than that of A533-B steel would result in a higher tendency for the formation of inclusions. This would further contribute to lowering the initiation energy $\mathrm{E}_{\mathrm{i}}$ of the $308 \mathrm{WM}$.
The role played by the difference in the dynamic strain capacity of the investigated materials should be taken into consideration. The values of $\sigma_{\mathrm{y}} / \sigma_{\mathrm{m}}$ and $\delta$, as deduced from load-time traces at $150{ }^{\circ} \mathrm{C}$, reflects much higher deformation capacity of the A533-B than that of the 308 WM. This means a less amount of plastic deformation for the ductile fracture processes(void growth, coalescence) of the 308 WM. In addition, the microstructure morphology of the 308 WM (vermicular delta ferrite) could also have contributed more to the coalescence process of voids [7]. This results in the consumption of a lower amount of energy in both the initiation and propagation processes of the 308 WM ductile fracture leading to a reduction in the impact toughness energy.

The observed reduction of the impact toughness of the $308 \mathrm{WM}$, still with a ductile fracture manner, as the test temperature was reduced from 150 to $100{ }^{\circ} \mathrm{C}$ can be associated with the presence of the $5 \%$ ferrite phase in the austenitic matrix. Despite the fact that ferrite tends to experience cleavage failure at low temperatures, it is apparent that the austenite phase has dominated the fracture mechanism by resisting the extension of brittle cleavage cracks that might form within the delta ferrite network.

The noticeable difference in the values of initiation and propagation energy can be accounted for in view of the difference between the two processes. Initiation is fundamentally a two-dimensional process where crack blunting takes place effectively in the straight ahead direction. In such case, only those parameters associated with this direction will be important. Propagation, however, occurs by linkage of voids which are spatially distributed, so that second phase particle parameters of all three dimensions must be considered. The result is that the state of these parameters (volume fraction, shape, size ) should be taken into account [8].

\section{Brittle fracture}

The ductile to brittle transition behavior of the A533-B steel (Fig. 2) could be a direct consequence of the temperature dependence of the yield stress of ferritic steels, i.e. increasing rapidly with decreasing temperature. As shown earlier, the dynamic yield strength $\sigma_{\mathrm{yd}}$ of the A533-B steel increased from 550 to $750 \mathrm{MPa}$ as the test 
temperature decreased from 150 to $-100{ }^{\circ} \mathrm{C}$. This drop in oyd was associated with a change in the dynamic strain capacity indices. The $\mathrm{P}_{\mathrm{y}} / \mathrm{P}_{\mathrm{m}}$ index increased from 0.6 to 0.8 while the deflection index $\delta$ decreased sharply from 0.55 to $0.02 \mathrm{~mm}$, both indicating dramatic loss in the amount of plastic deformation. Moreover, the fracture surface morphology changed totally from dimpled rupture at $150{ }^{\circ} \mathrm{C}$ to cleavage fracture facets at $-100{ }^{\circ} \mathrm{C}$.

Cleavage fracture takes place through the nucleation and propagation of cleavage cracks. Nucleation of cleavage microcracks occurs through a mechanism that may operate by piling up dislocations at carbide particles leading to cracking of either the particles or the carbide matrix interface [9]. The relatively high carbon content of the A533-B (0.25\%), Table (1) suggests high volume fraction of carbide particles, which would then enhance the nucleation of cleavage microcracks.

In contrast, the brittle crack propagation process depends on the magnitude of the local tensile stress $\sigma_{y y}$ ahead of the notch root. $\sigma_{y y}$ is a multiple of the material yield strength $\sigma_{y}$ due to stress concentration. For crack propagation to commence, $\sigma_{\mathrm{yy}}$ must exceed a critical stress level; cleavage fracture strength $\sigma_{\mathrm{F}}$. The cleavage fracture strength is a characteristic of the material's microstructure and is not temperature dependent. Thus, an increase in $\sigma_{\mathrm{y}}$ (as temperature is decreased) would lead to increasing $\sigma_{\mathrm{yy}}$ value till it surpasses that of $\sigma_{\mathrm{F}}$, Fig. (7). In this event, it would become much easier for the material to experience brittle crack propagation rather than to exert ductile plastic deformation [9]. In addition, the anticipated high volume fraction of carbide particles, as mentioned above, would contribute to promoting the brittle fracture crack propagation through increasing the yield strength in the first place.

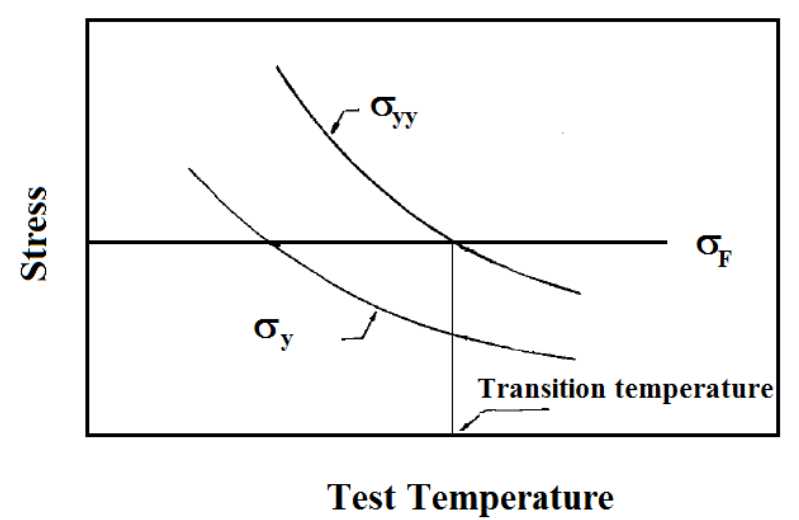

Fig. (7): Schematic showing the relation between the yield strength $\left(\sigma_{y}\right)$, the local tensile stress $\left(\sigma_{y y}\right)$ and the cleavage fracture strength $\left(\sigma_{\mathrm{F}}\right)[9]$

\section{Conclusions}

The impact toughness of the ferritic pressure vessel steel A533-B and its 308 austenitic stainless steel weld metal were determined at various test temperatures using instrumented impact testing machine. The following conclusions could be drawn:

1) The A533-B steel exhibits distinct ductile-tobrittle transition behavior with greater resistance to ductile fracture at high test temperatures. In contrast, the 308 weld metal show a gradual reduction in the ductile fracture energy with higher resistance to brittle failure at low test temperatures.

2) The inferior ductile fracture energy of the 308 weld metal as compared to that of the A533-B steel (135 vs. $70 \mathrm{~J})$ is mainly due to the much reduced value in its crack propagation energy (90 vs. $42 \mathrm{~J}$ ) than in its crack initiation energy (45 vs. $28 \mathrm{~J})$.

3) The sustained ductile fracture of the 308 weld metal at low temperatures can be a result of the dominating effect of the austenite phase on the failure mechanism in addition to the limited percent $(5 \%)$ of the delta ferrite phase.

4) The dynamic stain capacity indices; the ratio of the yield to the maximum load and the entire deflection, as deduced from the loadtime traces, can be employed to express the amount of plastic deformation and flow properties at both high and low test temperatures. 


\section{References}

1-G. Odette, G. Lucas, Embrittlement of nuclear reactor pressure vessels, JOM, Vol. 53, Issue 7 (2001)18-24

2-T. Tobita, M. Udagawa, Y. Chimi, Y. Nishiyama, K. Onizawa, Effect of neutron irradiation on the mechanical properties of weld overlay cladding for reactor pressure vessel, J. Nuclear Materials, Vol.452 (2014) 61-68.

3-N. Rao, G. Reddy, S. N. Agarjuna, Weld overlay cladding of high strength low alloy steel with austenitic stainless steel-Structure and Properties, Materials \& Design,Vol.32, Issue 4 (2011) 24962506.

4-S. A. David, J. M. Vitec, and D.J. Alexander, Embrittlement of Stainless Steel Welds, J. of Nondestructive Evaluation, Vol.15. Nos. 3/4 (1996) 129-135

5-M.M. Goniem and M. Rieth, Effect of aging and specimen size on the impact properties of MANET II steel, Int. J. Pres. Ves. Piping, Vol. 74 (1997) 39-47

6-A. Amine Benzerga and Jean-Baptiste Leblond, Ductile Fracture by Void Growth to Coalescence,
Advances in Applied Mechanics, Vol. 44, (2010) 169-305

7-D. J. Gavenda, W. F. Michaud, T. M. Galvin, W. F. Burke, and O. K. Chopra, Effects of Thermal Aging on Fracture Toughness and Charpy-Impact Strength of Stainless Steel Pipe Welds, NUREG/CR-6428 ANL-95/47

8-R. O. Ritichie and A. W. Thompson, On macroscopic and microscopic analyses for crack imitation and crack growth toughness in ductile alloys, Metallurgical Transaction A, Vol. 16, 1 (1985) 233248

9-A.M. Nasredin, M.M. Ghoneim, F. H. Hammad, R. L. Klueh and R.K. Nanstad, Effect of Tempering on the Toughness of a Cr-Mo Bainitic Steel, J. Mat. Eng. and Perf., Vol.2 (1993) 413-420 